\title{
A study of meiosis and spermiogenesis in the testicular lobes of Antiteuchus tripterus (Heteroptera: Pentatomidae)
}

\author{
Herderson Vinicius de SOUZA ${ }^{1}$ Hermione Elly Melara de CAMPOS BiCUdO ${ }^{1}$, Luiz Antônio Alves COSTA² \\ and Mary Massumi ITOYAMA ${ }^{1 *}$ \\ ${ }^{1}$ Universidade Estadual Paulista, Instituto de Biociências, Letras e Ciências Exatas, UNESP/IBILCE, Departamento de Biologia, \\ Laboratório de Citogenética de Insetos, Rua Cristóvão Colombo, 2265, Jardim Nazareth, CEP: 15054-000, \\ São José do Rio Preto, SP, Brasil \\ ${ }^{2}$ Museu Nacional, Departamento de Entomologia, Rio de Janeiro, Brasil
}

Key words. Heteroptera, Pentatomidae, meiosis, spermatozoa, testicular lobes, harlequin lobe

\begin{abstract}
An analysis of testicular morphology and spermatogenesis in the Heteroptera species Antiteuchus tripterus (Pentatomidae) revealed that these traits differ from that recorded for other species of the same family. The testes of $A$. tripterus have only six lobes, while other species of the same family typically have seven lobes, including a compound lobe, i.e., a lobe containing another in its lumen. A study of meiosis and sperm structure in the different lobes of A. tripterus revealed a conventional meiosis in the lobes numbered one to three. In lobe four, however, prophase I spermatocytes exhibit the morphological characteristics of the so called "diffuse" stage and are larger than those in lobes $1-3$ in this and the remaining phases of meiosis. Thus, the resulting spermatids are not only larger but also their head is morphologically different. Lobe 5 exhibits characteristics known from other Pentatomidae species such as an uneven distribution of chromatin to the daughter cells, which give rise to cells of different sizes. This lobe forms spermatozoa of different sizes. Lobe 6 , contained within lobe 5, differs from it by having larger cells at a stage similar to the so called "diffuse" and spermatid tails with cross divisions, which are not found in other lobes and unreported in the literature.
\end{abstract}

\section{INTRODUCTION}

Several organisms produce different kinds of spermatozoa. The differences include cytogenetic and/or morphological variations. The regular production of cytogenetically differentiated spermatozoa was first described in gastropods in 1836 (Seibold, 1836, cited in Hodgson, 1977), and is now known to occur in several invertebrates, such as spiders (Rosati et al., 1970), centipedes (Jamieson, 1986) and many insects (Sivinski, 1980). Moths and butterflies, for example, produce both nucleate and anucleate spermatozoa; and some bedbugs and beetles produce spermatozoa with a very variable number of chromosomes (Swallow \& Wilkinson, 2002; Friedländer et al., 2005). Morphological variations may also affect spermatozoal size, as observed in some bedbugs and beetles, length, as in some flies and shape, as in some wasps (Swallow \& Wilkinson, 2002).

Heteroptera of the family Pentatomidae, the object of this study, are also an example of organisms with variable spermatozoa. In all the previously studied species of this family, testes consist of a number of compartments referred to as "lobes". Most frequently there are seven lobes, but some variation occurs among tribes and species. In the Pentatomidae, spermatozoa of different size, ploidy, or both, are produced by different lobes, but studies on spermatogenesis development in each testicule lobe of a Pentatomidae are scarce (Swallow \& Wilkinson, 2002).
In the Pentatomidae, chromosomal characteristics are basically the same as in other Heteroptera: they are holokinetic, i.e., they have no localized centromere, which causes microtubules to bind to the entire chromosomal surface during mitosis and the sister-chromatids migrate in parallel to the cell pole at anaphase (Buck, 1968; Comings \& Okada, 1972). At meiosis, however, the kinetic activity is restricted to telomeric regions, and chromosomes are, therefore, denominated telokinetic (Motzko \& Ruthmann, 1984). Meiotic behavior is slightly different among bivalent autosomes, sex chromosomes and micro-chromosomes (Ueshima, 1979; Manna, 1984; Papeschi \& Mola, 1990; González-Garcia et al., 1996; Suja et al., 2000). Except in a few species, bivalent autosomes are chiasmatic while stick-shaped bivalents are axially oriented and segregate pre-reductionally (Nokkala \& Grozeva, 2000). On the other hand, sex chromosomes are achiasmatic and behave as univalents at male meiosis, equationally divide at anaphase I and associate to form a pseudo-bivalent at meiosis II. Nonetheless, the prereduction of sex chromosomes is also reported in some species (Ueshima, 1979; Grozeva \& Nokkala, 2001). The pair of micro-chromosomes is also achiasmatic, but its components associate at first division and segregate prereductionally.

The purpose of this work was to analyze the morphology of testes in the pentatomid Antiteuchus tripterus, as well as the process of meiosis and spermiogenesis

\footnotetext{
* Corresponding author; e-mail: mary@ibilce.unesp.br
} 

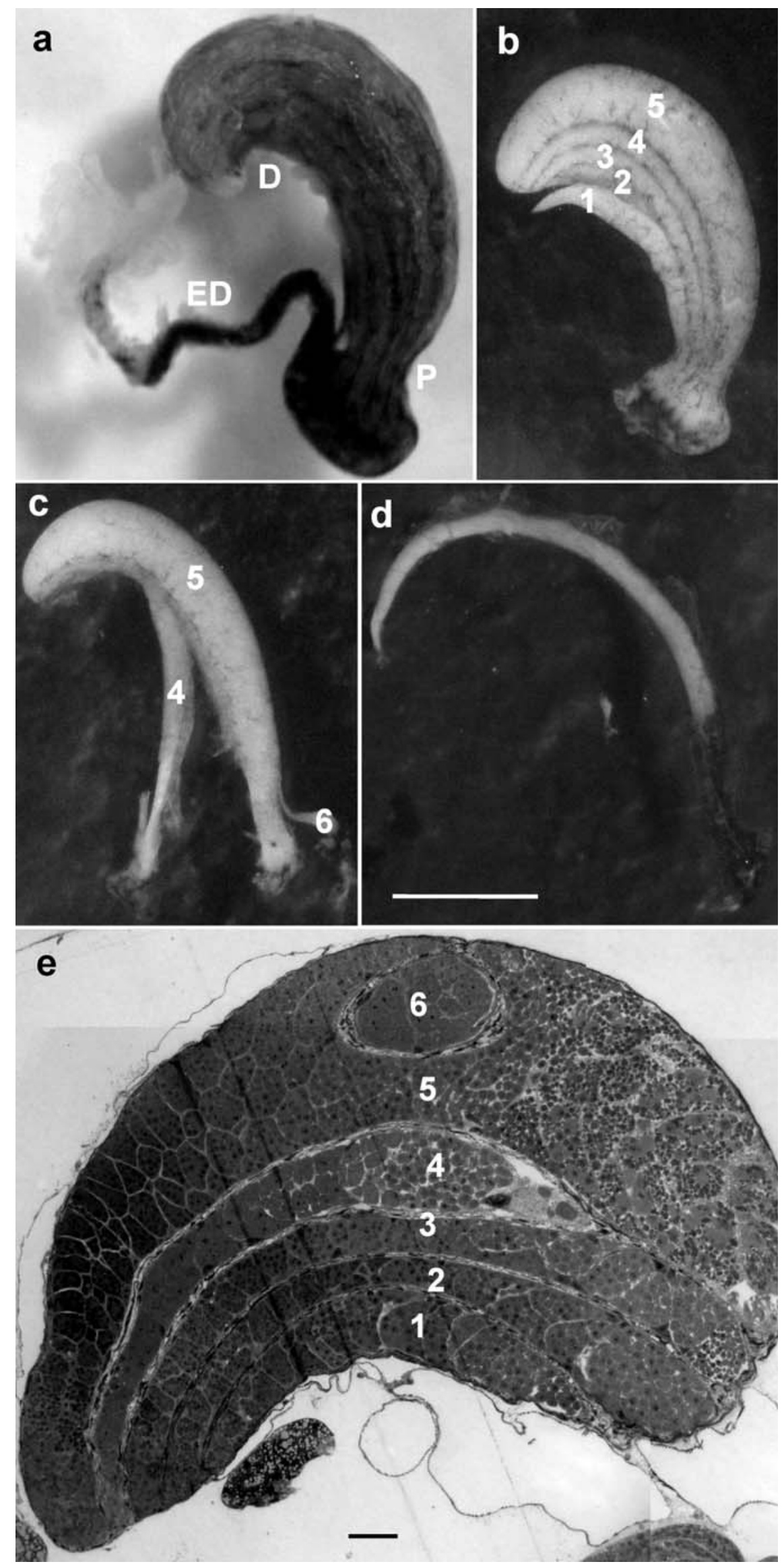

Fig. 1. Testis of an adult male Antiteuchus tripterus after treatment with trypsin. a - distal region (D), proximal region (P) and ejaculatory duct (ED); b - testicular lobes $1-5$; $\mathrm{c}$ - testicular lobes 5 and 6 (inside 5); $\mathrm{d}$ - testicular lobe 6; e - histological longitudinal section of the testicular lobes. Bar $=10 \mu \mathrm{m}(\mathrm{a}-\mathrm{d}), 30 \mu \mathrm{m}(\mathrm{e})$. 
separately in each testicular lobe. As far as we are aware, this is the first attempt at this kind of a separate analysis.

\section{MATERIAL AND METHODS}

Adult males of Antiteuchus tripterus (Fabricius) (Heteroptera: Pentatomidae) were collected from the plant Bauhinia punctata Bolle (Fabaceae), in São José do Rio Preto, SP, Brazil. For the analysis of testicular morphology as well as aspects of meiosis and spermatozoal production, testes were removed and placed in Demerec solution on a slide (Demerec \& Kaufmann, 1945) and then incubated for $20 \mathrm{~min}$ after adding a drop of trypsin and EDTA solution $(0.005 \mathrm{~g}$ of trypsin and $0.002 \mathrm{~g}$ of EDTA diluted in $10 \mathrm{~mL}$ of Hank's solution: $1.4 \mathrm{mM} \mathrm{NaCl}, 70 \mathrm{mM} \mathrm{KCl}, 4.2$ $\mathrm{mM} \mathrm{Na} 2 \mathrm{HPO}_{4}, 3 \mathrm{mM} \mathrm{KH_{2 }} \mathrm{PO}_{4}, 5 \mathrm{mM}$ glucose, $0.045 \mathrm{mM}$ phenol red). The lobes were separated, transferred to slides and fixed in methanol : acetic acid ( $3: 1)$ for $15 \mathrm{~min}$ and subsequently methanol : acetic acid $(1: 1)$ for $10 \mathrm{~min}$.

For the analysis of meiosis and spermatozoal production, each lobe was placed separately on a slide, stained with lactic acetic orcein and squashed. Images were obtained using a Zeiss microscope and AXIO VISION software for image analysis. Measurements were taken with Micromeasure version 3.3 (Reeves \& Tear, 2000).

Forty individuals were used for gonad and lobe separation and ten slides were analyzed per lobe for recording cell characteristics. For histological analysis, testes were fixed with Karnovsky solution and embedded in Araldite (Glauert, 1975). Sections were stained with haematoxylin-eosin and toluidine blue for general morphology.

\section{RESULTS}

Antiteuchus tripterus testes are covered by a reddish membrane and are curved with the distal region larger than the proximal region, where the ejaculatory duct is located (Fig. 1a). After treating the testis with trypsin, a total of five individual lobes per testis can be identified (Fig. 1b). Three of the lobes are of the same size (lobes 1, 2 , and 3), one is thinner (lobe 4) and the other longer (lobe 5). Lobe 5 contains within it another tubule, which is lobe 6 (Fig. 1c). The use of $45 \%$ acetic acid causes lobe 5 to dissociate, which makes it possible to isolate lobe 6 . A drop of methanol: acetic acid $(3: 1)$, which makes the inner lobe more evident and rigid, facilitates its separation (Fig. 1d). Histological sections confirmed the arrangement of the lobes in the testes (Fig. 1e). Meiotic behaviour and the types of spermatozoa produced in each lobe were studied separately.

\section{Testicular lobes 1 to 3}

Lobes 1-3, after lactic acetic orcein staining and squashing, show nutritive cells with large polyploid nuclei, which carry several heteropycnotic bodies (Fig. 2a). In these lobes, spermatogenesis is cystic, usually consisting of eight spermatogonia per cyst. Each spermatogonium displays one or more heteropycnotic bodies (Fig. 2b).

Cytogenetic analysis revealed that the chromosomal complement is $2 \mathrm{n}=14(12 \mathrm{~A}+\mathrm{XY})$ in A. tripterus males (Fig. 2f). The cells at meiotic prophase I exhibit one or two heteropycnotic bodies of different size that are likely to correspond to the sex chromosomes $\mathrm{X}$ and $\mathrm{Y}$, which are seen together or apart, and, most frequently, are found at the periphery of the nucleus (Fig. 2c, d). Diplotene, autosome bivalents show terminal or interstitial chiasmata, and very often exhibit complex telomeric associations (Fig. 2e). The sex chromosomes do not form chiasmata, but are frequently close to each other. At metaphase I, autosomes may appear arranged in a circle with the sex chromosomes inside (polar view) (Fig. 2f). One of the six autosome pairs is noticeably larger than the others.

The first autosome division is reductional, i.e., the homologous chromosomes are separated (Fig. 2g). The equational division of autosomes occurs at anaphase II (Fig. 2h). In contrast, the sex chromosomes usually show equational separation of sister-chromatids at anaphase I, and reductional at anaphase II. The late migration of the sex chromosomes, as well as the heteropycnotic body can be seen at telophase (Fig. 2i). In the spermatids, which are still round, the heteropycnotic chromatin can also be observed near the periphery of the nuclear envelope; this chromatin remains in the same position when the spermatid elongates to form the head and tail of the spermatozoon (Fig. 2j, k). Initially, the spermatozoa have a long and thin head (Fig. 21), but later develop a small head and a very long tail (Fig. $2 \mathrm{~m}$ ).

\section{Testicular lobe 4}

In lobe 4, the morphology of the cells at prophase is similar to that of the so called "diffuse" stage cells (Tartarotti \& Azeredo-Oliveira, 1999). They exhibit a large amount of cytoplasm, decondensed chromatin and heteropycnotic granules of different sizes (Fig. 3a). Because nuclei are round, their diameter was used to compare prophase I cells from different lobes. Mean values of spermatocyte nuclei based on 10 measurements in each lobe were, for lobe 1-3 and 5: $29 \pm 2 \mu \mathrm{m}$; for lobe 4: $64 \pm 3$ $\mu \mathrm{m}$; for lobe $6: 47 \pm 1 \mu \mathrm{m}$. In lobe 4 , nuclei are 2.2 times larger than in lobes $1-3$ and 5 and 1.36 times larger than in lobe 6 . The cells at metaphase II show telomeric associations of sister chromatids (Fig. 3b). The size of the cells at anaphase II and telophase II is similar to that of the cells at "diffuse" stage (Fig. 3c, d). In the spermatids, the heteropycnotic material is at the periphery of the nucleus and is almost totally occupied by a large vesicle (Fig. 3e). As spermiogenesis advances, the heteropycnotic material becomes less evident and is located in the anterior part of the head of the forming spermatozoon (Fig. 3f). The posterior part of the head has a region of increased diameter, where the external membrane appears to be "pleated", but, at the end of the process, these spermatids also become longer and thinner (Fig. $3 \mathrm{~g}$ ). No polyploid cells were observed in this lobe.

\section{Testicular lobe 5}

In lobe 5 , the cells at early meiotic prophase I are similar to those in lobes $1-3$, i.e., the nucleus has one or two heteropycnotic bodies at the periphery or associated with chromosomes (Fig. 4a). The cells found in this lobe display variable associations between chromosomes as they condense (Fig. 4b, c). At metaphase I, some chromosomes, probably the sex chromosomes, do not show the 

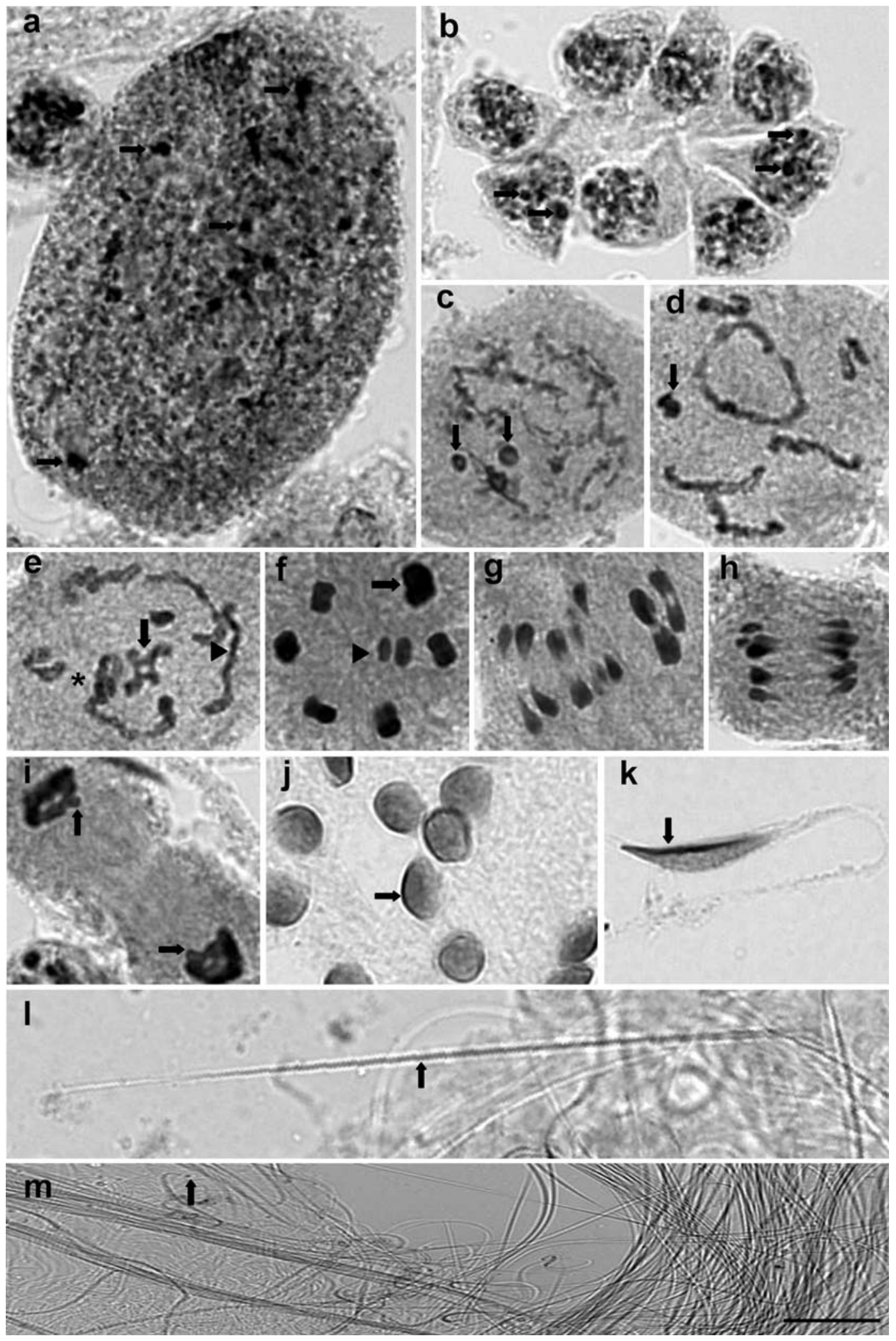

Fig. 2. Germ cells from testicular lobes 1-3 of Antiteuchus tripterus stained with lactic acetic orcein. a - several heteropycnotic regions (arrows) in the polyploid nucleus of a nutritive cell from the tubule wall; $b$ - cyst containing 8 spermatogonia; arrows indicate heteropycnotic regions; c - spermatocyte at prophase I (zygotene) with 2 separate heteropycnotic bodies (arrows); d - diplotene spermatocyte showing two associated heteropycnotic bodies (arrow); e - diplotene spematocyte showing terminal (arrow-head) or interstitial (arrow) chiasmata and complex telomeric associations (arrow-head); f - metaphase I showing 6 autosome bivalents arranged in a circle; the arrow indicates the largest autosome bivalent, the arrow-head indicates the $\mathrm{X}$ and $\mathrm{Y}$ sex chromosomes situated inside the circle; $g$ - anaphase I spermatocyte; $h$ - anaphase II spermatocyte; $i$ - telophase with late migration of the sex chromosomes (arrows); $\mathrm{j}$ - round spermatids with heteropycnotic chromatin (arrow) located at the periphery of the nucleus; $\mathrm{k}-$ elongated spermatid with heteropycnotic chromatin located at the periphery of the head (arrow); 1 - spermatid with a long and thin head (arrow); $\mathrm{m}-$ spermatozoon with a small head (arrow) and long tail. Bar $=10 \mu \mathrm{m}$. 


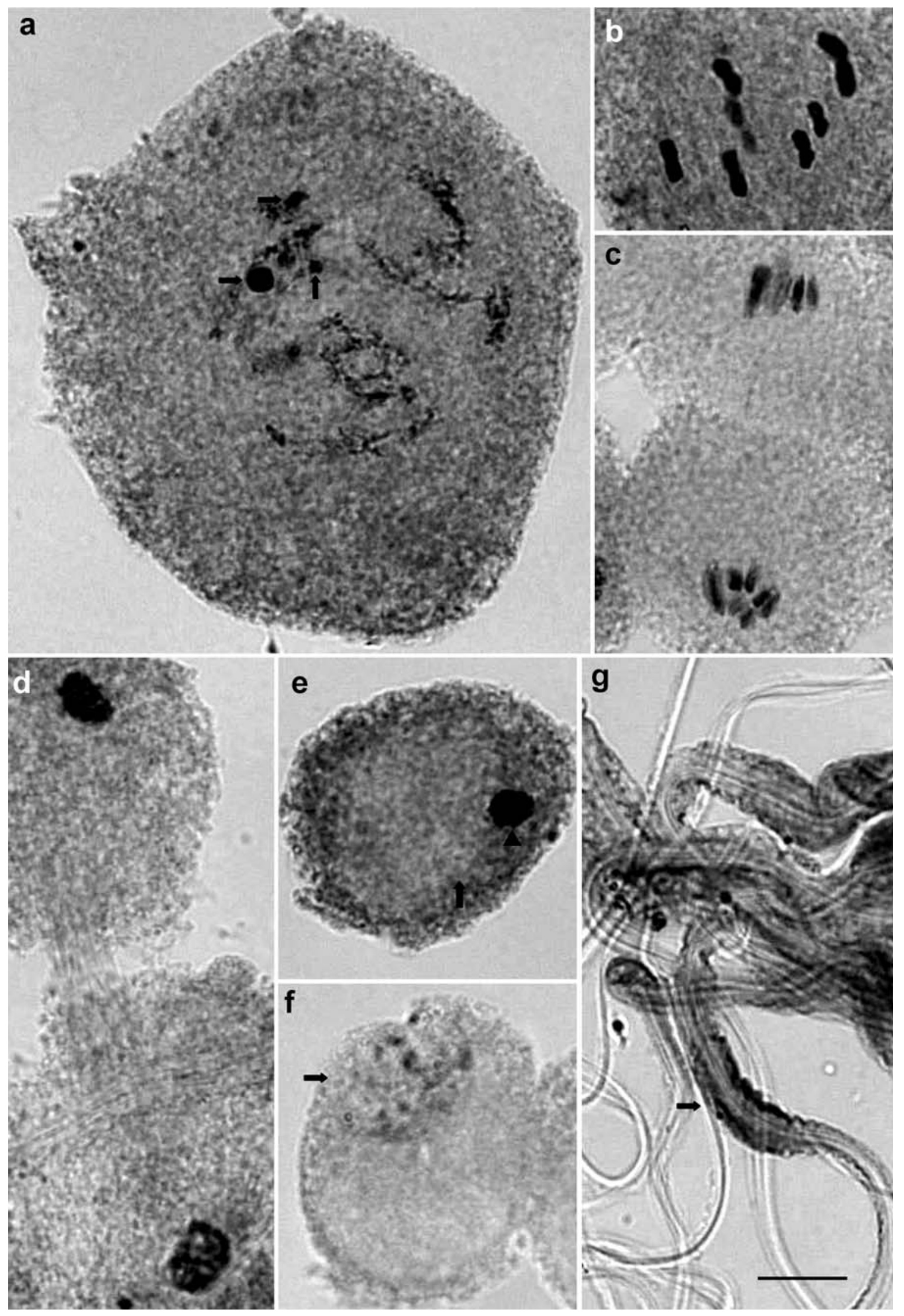

Fig. 3. Germ cells from testicular lobe 4 of Antiteuchus tripterus stained with lactic acetic orcein. a - cell at prophase I ("diffuse" stage) with decondensed chromatin and heteropycnotic granules of different sizes (arrows); $b$ - at metaphase II with telomeric association of sister chromatids; $\mathrm{c}-$ at anaphase II; $d$ - at telophase; notice that these cells are larger than those in lobes 1-3 (cf. Fig. 2i); $\mathrm{e}$ - spermatid with heteropycnotic material (arrow-head) and a large vesicle (arrow); $\mathrm{f}$ - decondensed chromatin in the spermatid nucleus (arrow); $\mathrm{g}-$ the posterior region of the head of elongated spermatids is broad and has a pleated membrane $(\operatorname{arrow})$. Bar $=10$ $\mu \mathrm{m}$. 
TABLE 1. Summary of the main cytogenetic and morphological characteristics of the lobes of testes in Antiteuchus tripterus (Heteroptera: Pentatomidae).

\begin{tabular}{|c|c|c|}
\hline Lobes & Meiosis & Spermiogenesis \\
\hline 1 to 3 & $\begin{array}{l}\text { - Polyploid cells with several heteropycnotic bodies of } \\
\text { different sizes } \\
\text { - Prophase I cells exhibit one or two heteropycnotic } \\
\text { bodies of different size } \\
\text { - Autosomes show terminal or interstitial chiasmata } \\
\text { - Sex chromosomes do not form chiasmata } \\
\text { - At metaphase I autosomes are often arranged in a circle } \\
\text { with the sex chromosomes inside }\end{array}$ & $\begin{array}{l}\text { Spermatids } \\
\text { - Heteropycnotic material located at the periphery of the } \\
\text { nucleus } \\
\text { Spermatozoon } \\
\text { - Apparently normal }\end{array}$ \\
\hline 4 & $\begin{array}{l}\text { - Lack polyploid cells } \\
\text { - Prophase I cells have "diffuse" stage, heteropycnotic } \\
\text { granules of different sizes and large amount of } \\
\text { cytoplasm }\end{array}$ & $\begin{array}{l}\text { Spermatids } \\
\text { - Heteropycnotic material located at the periphery of the } \\
\text { nucleus } \\
\text { - Nucleus almost entirely occupied by a large vesicle } \\
\text { - Membrane at the posterior end of the head "pleated" } \\
\text { Spermatozoon } \\
\text { - Apparently normal }\end{array}$ \\
\hline 5 & $\begin{array}{l}\text { - Lack polyploid cells } \\
\text { - Prophase I cells have one or two heteropycnotic bodies } \\
\text { of different size } \\
\text { - Chromosomes not individually apparent at any phase } \\
\text { during meiosis } \\
\text { - Uneven and variable chromatin distribution at anaphase }\end{array}$ & $\begin{array}{l}\text { Spermatids } \\
\text { - Three different sizes (small, medium and large) }\end{array}$ \\
\hline 6 & $\begin{array}{l}\text { - Large polyploid nuclei with a large number of } \\
\text { heteropycnotic bodies of different sizes } \\
\text { - Prophase I cells show "diffuse" stage with one or two } \\
\text { heteropycnotic bodies of different size } \\
\text { - Cells at metaphase or anaphase not observed } \\
\text { - Many telophase cells }\end{array}$ & $\begin{array}{l}\text { Spermatids } \\
\text { - A large vesicle inside the nucleus that is smaller than in } \\
\text { lobe } 4 \\
\text { - Membrane at the posterior end of the head "pleated" } \\
\text { - Transverse partitions at variable intervals in the "pleated" } \\
\text { region of the head } \\
\text { Spermatozoon } \\
\text { - Apparently normal }\end{array}$ \\
\hline
\end{tabular}

same degree of staining as the other chromosomes as in lobe 1 to 5. Moreover, in lobe 5, autosomes agglomerate and the sex chromosomes usually remain apart (Fig. 4d, e). At anaphase I, there is an uneven and variable chromatin distribution. As a result, some cells contain larger amounts of chromatin than others (Fig. $4 \mathrm{f}-\mathrm{h}$ ). At the end of the meiotic process, the spermatids contain different quantities of chromatin (Fig. 4i-k), which is mainly around the nuclear envelope (Fig. 4j, k). As spermiogenesis progresses, chromatin distribution is restricted to the region of the nuclear envelope, where it remains when the spermatids elongate (Fig. $4 \mathrm{j}-1$ ).

Regarding size, at least three types of spermatids are observed: small, medium and large (Fig. 4k, 1). As the process continues, the head becomes thinner, but the three different sizes are still detectable (Fig. $4 \mathrm{~m}-\mathrm{o}$ ). The head of a spermatozoon is long and thin with chromatin located in the posterior region (Fig. 4o). In this lobe, no polyploid cells were observed.

\section{Testicular lobe 6}

Lobe 6 , located in lobe 5 , has large polyploid nuclei and a significantly larger number of heteropycnotic bodies than lobes 1-3 (Fig. 5a). In meiotic prophase I spermatocytes, the mean size of the nucleus is 1.36 times smaller than in lobe 4 and 1.6 times larger than in lobes 1-3 and 5. Each nucleus shows a large heteropycnotic body located at the periphery and a "diffuse" stage aspect
(Fig. 5b). In this lobe, many cells were observed at telophase (Fig. 5c), but none at metaphase or anaphase. At early spermiogenesis, the nucleus is large with the heteropycnotic chromatin located at the periphery of the nuclear envelope, and is inside a vesicular formation. When spermatids start to form a tail, chromatin remains located at the periphery of the nucleus and the vesicle moves to the head region close to the tail (Fig. 5d). The membrane that covers the posterior region of the head is "pleated" and this disappears as spermatids elongate (Fig. 5e). Then, transverse partitions are formed at irregular intervals in this region, which divide it into subregions of different lengths (Fig. 5f). Later, the spermatozoa are similar to those in other lobes, with a small head and long tail. A summary of the morphological and cytogenetics characteristics found at meiosis and spermatogenesis in the lobes is shown in Table 1.

\section{DISCUSSION}

Montgomery (1898 apud Schrader, 1960b) first established three classes of spermatozoa in the Pentatomidae: large, medium, and small. In the pentatomid Arvelius albopunctatus (De Geer), large spermatozoa are approximately 8 times bigger than those in the small category (Schrader \& Leuchtenberger, 1950, 1951). In all cases, the production of spermatozoa of different sizes is associated with the presence of multiple testicular lobes. It is noteworthy that, according to these authors, spermatozoa 

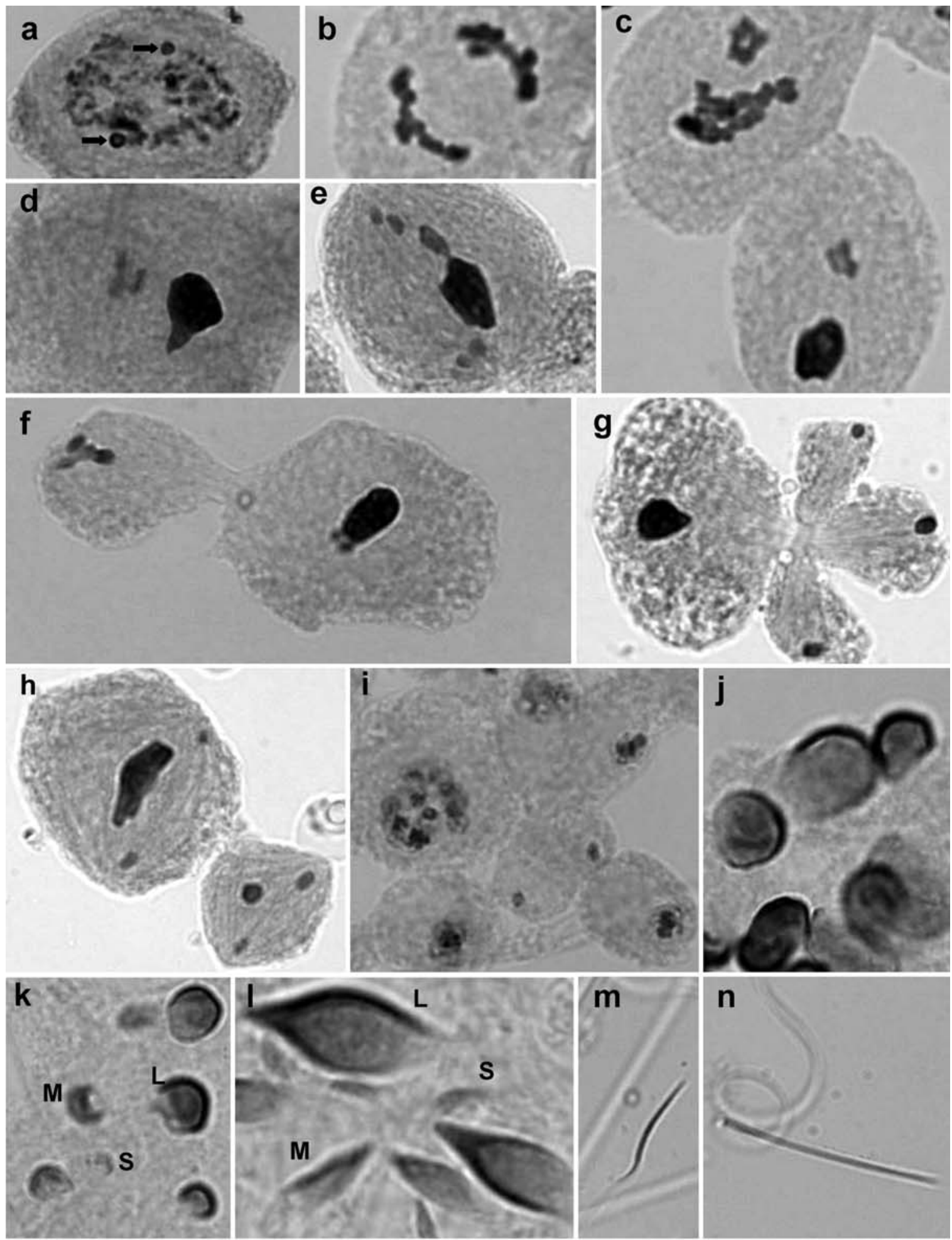

n

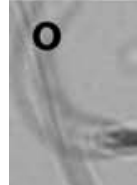

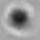

Fig. 4. Germ cells from testicular lobe 5 of Antiteuchus tripterus stained with lactic acetic orcein. a - at early meiotic prophase I with two heteropycnotic regions, associated or not with chromosomes (arrows); b, c - at meiotic prophase I; notice the different kinds of chromosomal association; $\mathrm{d}$, e - at metaphase I with autosomes forming a large agglomerate separate from the sex chromosomes; $\mathrm{f}-\mathrm{h}$ - at anaphase with uneven chromatin distribution among different cells; $\mathrm{i}$ - spermatids with different chromatin amounts; $\mathrm{j}$ - spermatids with heteropycnotic chromatin in only one region of the nuclear envelope; $\mathrm{k}$ - spermatids of different sizes: small (S), medium (M) and large (L); 1-O - spermatids of three sizes at different phases of elongation; notice the presence of heterochromatin in the posterior region of the head (o, arrow). Bar $=10 \mu \mathrm{m}$. 

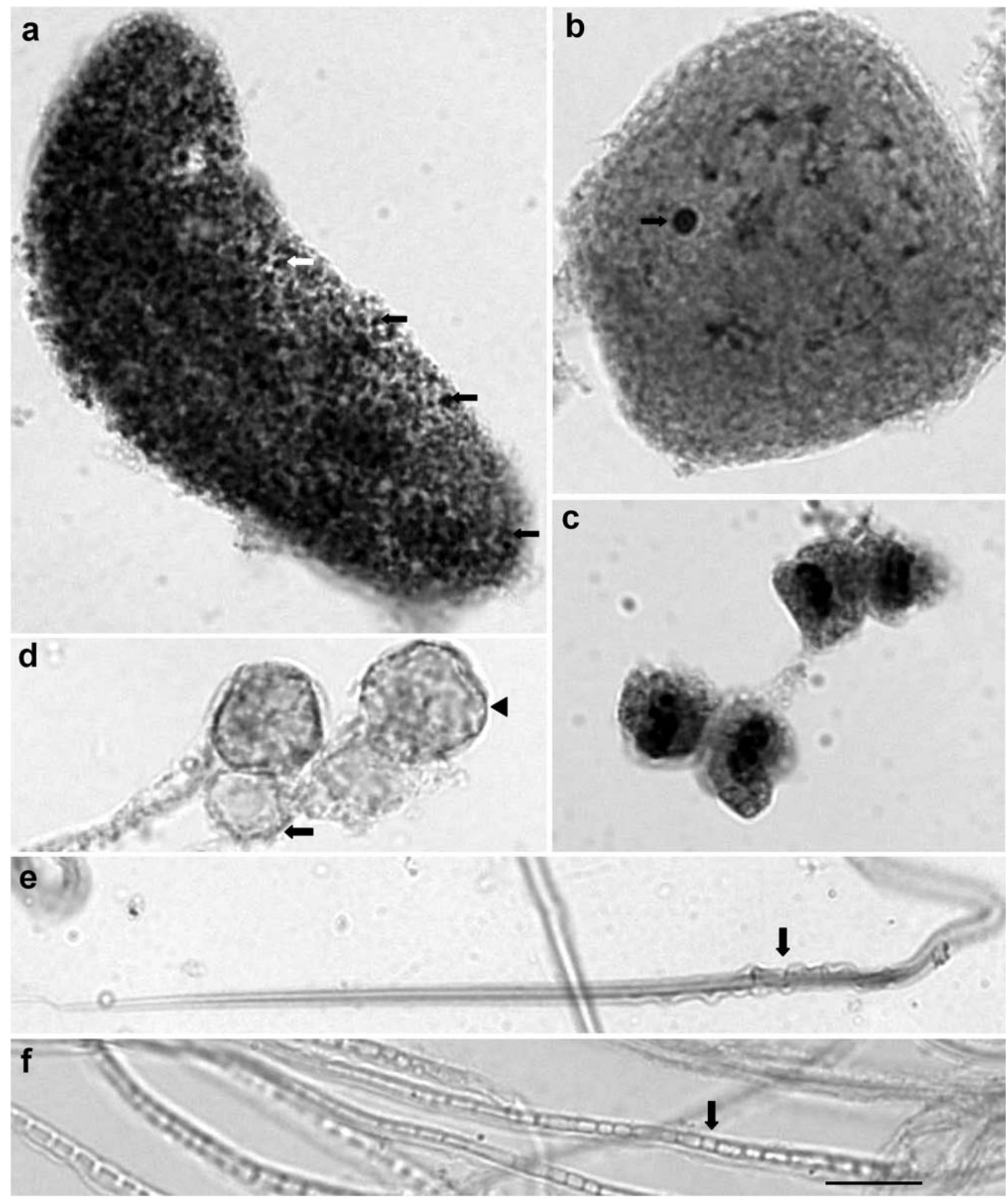

Fig. 5. Germ cells from testicular lobe 6 of Antiteuchus tripterus stained with lactic acetic orcein. a - several heteropycnotic bodies (arrows) in a polyploid nucleus of a nutritive cell from the tubule wall; b - at prophase I with a heteropycnotic body (arrow); $\mathrm{c}$ - four telophase cells; $\mathrm{d}$ - spermatids with heteropycnotic chromatin located at the periphery of the nuclear envelope (arrow-head) and large vesicle (arrow); e-f - elongating spermatid with a pleated membrane (arrow) in the posterior region of the head (e); as elongation progresses partitions develop at irregular intervals (f, arrow). Bar $=10 \mu \mathrm{m}$.

of different sizes result from normal meiosis. Thus, spermatozoal size would positively correlate with the content of protein and RNA found in the different spermatozoal classes, while the haploid number of chromosomes remains constant. The size of spermatocytes does not correlate with lobe size, as the lobe that produces the smallest spermatozoa in these organisms is frequently the largest and that which produces the largest spermatozoa 
the smallest lobe (Schrader \& Leuchtenberger, 1950; 1951; Schrader, 1960a, b).

Another process, polymegaly, observed in a few species belonging to the subfamily Pentatomidae, results in spermatozoa of not only different sizes but also different ploidies (Bowen, 1922a, b; Schrader, 1960a, b). In a review, Rebagliati et al. (2005) mention the presence of harlequin lobes and abnormal meiosis occuring in 22 species of 15 genera of Pentatomidae. In the genus Loxa, the number of chromosomes seen in the developing spermatids derived from this lobe varies from 1 (always the sex chromosome) to 100 , which is 10 times the haploid number of chromosomes found in this genus (Bowen, 1922a, b; Schrader, 1945a, b; Lanzone \& Souza, 2006).

Spermatozoal size is proportional to chromosome number. Even if spermatozoal development is not affected by chromosome number, current evidence indicates that only those with at least one complete chromosome complement reach the ejaculatory duct (Schrader, 1960a). Thus, smaller spermatozoa, with chromosomes numbers less than the haploid number, never leave the male reproductive system.

Schrader (1945a, 1960a, b) was surprised to verify that harlequin lobes persist throughout the evolutionary process although they are structures that produce heteropolyploid spermatozoa not used in fertilization. This author suggests that heteropolyploid spermatozoa supply nutrients, especially nucleoproteins, for the development of the eggs. The harlequin spermatozoa are likely to be infertile. However, neither the regular occurrence of polyspermia, in general, nor the entrance of harlequin spermatozoa into eggs, in particular, has been investigated in Pentatomidae (Swallow \& Wilkinson, 2002). Heteropolyploid spermatozoa, though not observed by Schrader, could also have nutritive roles (i.e., for females or for fertilizing spermatozoa) (Swallow \& Wilkinson, 2002).

Even though previous studies report the production of different types of spermatozoa by different lobes, they do not identify which lobe forms which type of spermatozoa. This is reported in the present study, which demonstrated that $A$. tripterus testis consist of 6 lobes, classified as 1 to 6 , each with its own morphological characteristics.

Four of the lobes are small and simple and the largest, which contains another lobe, is designated a compound lobe. This compound lobe has not been previously described in any organism. Also characteristic of $A$. tripterus is the number of lobes (6), while the other species have seven.

A. tripterus lobes are longitudinally paired. In three of them (1-3), all phases of normal meiosis were observed, indicating similarity with meiosis in other Heteroptera. In particular we observed the presence of polyploid nuclei to assist nutrition, cystic meiosis, heteropycnotic sex chromosomes at prophase, formation of terminal or interstitial chiasmata, equational first autosomal division and reductional second autosomal division.

In the testicular lobe 4 of $A$. tripterus, however, no cells with the morphology characteristic of the different phases of meiosis were observed. In this lobe, meiotic prophase I cells are very large and their chromatin is descondensed as in "diffuse" stage. Metaphase, anaphase and telophase spermatocytes are found, with the same size as those in prophase I cells. However, the spermatids are larger than those in other lobes. A special characteristic of the spermatids in this lobe is the presence of a "pleated" membrane in the posterior part of the head.

The testicular lobe 5 of $A$. tripterus does not show prophase I spematocytes in "diffuse" stage. They are similar to those found in lobes $1-3$. Chromosomes associate differently at metaphase I forming agglomerates, in which sex chromosomes do not take part. Chromatin distribution among daughter cells is not equal, and the sizes of these cells also differ. The spermatids found in this lobe are the largest formed by $A$. tripterus and their heads are very big. Furthermore, this lobe forms spermatozoa of three different sizes. The characteristics observed in this lobe correspond to those of the harlequin lobe reported in the literature. According to Rebagliatti et al. (2005), a total of 22 species belonging to 15 different Pentatomidae genera have harlequin lobes with abnormal meiosis.

The testicular lobe 6 of $A$. tripterus, located inside lobe 5 , also has prophase I spermatocytes, similar to those at the diffuse stage, but larger than those in lobe 5 . This cell type and telophase cells were the only ones seen in the present analysis. In this lobe, as in lobe 4 a "pleated" membrane also occurs in the posterior region of the spermatid head, which disappears later. Peculiar to this lobe is the presence of transverse partitions in the same region, which distinguish them from the spermatids in other lobes.

Taken together, the observations in the present study show that the meiotic process in $A$. tripterus testes is similar in lobes 1,2 and 3, which in turn differs from that in the other lobes. In lobes 1-3, cells characteristic of the different meiotic phases are observed, whereas in each one of the other lobes a specific meiotic process takes place. In lobes 4 and 6 , there is a great increase in cell size, and a large vesicle is always seen inside the nucleus. Lobe 5, has a different meiotic pattern, which is responsible for the formation of spermatozoa of different sizes. The size of the spermatozoon in the other lobes is normal.

Taking into consideration that in Pentatomidae usually have seven lobes, A. tripterus appears to show an intermediate stage in the process of increase or reduction in lobe number. Reduction seems to be the more plausible because lobes 4 and 6 show a meiotic process very different from the conventional and may not form functional spermatozoa. It is also possible to suggest that the presence of the internal lobe facilitates the nutrition of the spermatozoa produced by the harlequin lobe, which would give it an important role and justify its retention in the evolutionary process. This hypothesis is corroborated by the presence of polyploid cells in lobe 6 and absence in lobe 5 .

In $A$. tripterus, the chromosome number is $2 \mathrm{n}=14$ $(12 \mathrm{~A}+\mathrm{XY})$, as recorded by Schrader $(1946,1960)$ and the pattern previously described for most Pentatomidae species (Rebagliatti et al., 2005). The observations 
described here show that the production of spermatozoa in A. tripterus is unusual. Further studies are necessary for a better understanding of this process and its function.

ACKNOWLEDGEMENTS. The authors thank S.M. Oliani and R.S. de Souza for help with the histological preparations Department of Biology and D.C.R. Feres - Department of Zoology and Botanic, IBILCE/UNESP for using the image capturer; as well as to FUNDUNESP and CNPq for their financial support.

\section{REFERENCES}

Bowen R.H. 1922a: Notes on the occurrence of abnormal mitosis in spermatogenesis. Biol. Bull. 43: 184-203.

Bowen R.H. 1922b: Studies on insect spermatogenesis. Proc. Am. Acad. Arts Sci. 57: 391-423.

Buck R.C. 1968: Mitosis and meiosis in Rhodnius prolixus: the fine structure of the spindle and diffuse kinetochore. J. Ultrastruct. Res. 18: 489-501.

Comings D.E. \& OKadA T.A. 1972: Holocentric chromosomes in Oncopeltus: kinetochore plates are present in mitosis but absent in meiosis. Chromosoma 37: 177-192.

Demerec M. \& Kaufmann B.P. 1945: Drosophila Guide. Baltimore Press, Baltimore, MA.

Friedländer M., Seth R.K. \& Reynolds S.E. 2005: Eupyrene and apyrene sperm: Dichotomous spermatogenesis in Lepidoptera. Adv. Insect Physiol. 32: 207-307

Glauert A.M. 1975: Fixation, dehydration and embedding of biological specimens. In Glauert A.M. (ed.): Practical Methods Electron Microscopy. Vol. 3. North Holland Publishing, New York, pp. 1-207.

González-Garcia J.M., Antonio C., Suja J.A. \& Rufas J.S. 1996: Meiosis in holocentric chromosomes: kinetic activity is randomly restricted to the chromatid ends of sex univalents in Graphosoma italicum (Heteroptera). Chromosome Res. 4: 124-132.

Grozeva S. \& Nokkala S. 2001: Chromosome numbers, sex determining systems, and patterns of the C-heterochromatin distribution in 13 species de Lace Bugs (Heteroptera, Tingidae). Folia Biol. (Kraków) 49: 29-41.

Hodgson A.N. 1977: Paraspermatogenesis in gastropod mollusks. Invert. Reprod. Dev. 31: 31-38.

JAMIESON B.G.M. 1986: The spermatozoa of Chilopoda (Uniramia): an ultrastructural review with data on dimorphism in Ethmostigmus rubripes and phylogenetic discussion. J. Submicrosc. Cytol. 18: 543-558.

Lanzone C. \& Souza M.J. 2006: Chromosome complement and meiosis in three species of the Neotropical bug genus Antiteuchus (Heteroptera, Pentatomidae, Discocephalinae). Genet. Mol. Biol. 29: 49-55.

ManNa G.K. 1984: Chromosomes in evolution in Heteroptera. In Sharma A.K. (ed.) Chromosomes in Evolution of Eukaryotic Groups. CRC Press, Boca Ratton, FL, pp. 189-225.

Motzko D. \& Ruthmann A. 1984: Spindle membranes in mitosis and meiosis of the heteropteran insect Dysdercus intermedius. A study of the interrelationship of spindle architecture and the kinetic organization of chromosomes. Eur. J. Cell Biol. 33: 205-216.

Nokkala S. \& Grozeva S. 2000: Aquiasmatic male meioses in Myrmedobia coleoptrata (Fn.) (Heteroptera, Microphysidae). Caryologia 53: 5-8.

Papeschi A.G. \& Mola L.M. 1990: Meiotic studies in Acanonicus hahni (Coreidae, Heteroptera). I. Behavior of univalents in desynaptic individuals. Genetica 80: 31-38.

Rebagliati P.J., Mola L.M., Papeschi A.G. \& Grazia J. 2005: Cytogenetics studies in Pentatomidae (Heteroptera): A review. J. Zool. Syst. Evol. Res. 43: 199-213.

ReEves A. \& Tear J. 2000: MicroMeasure for Windows, version 3.3. Free program distributed by the authors over the Internet from http://www.colostate.edu/Depts/Biology/MicroMeasure.

Rosati F., Baggetti B. \& Dallai R. 1970: The spermatozoon of Arthropoda. X. Araneid and the lower myriapods. In Baccetti B. (ed.): Comparative Spermatology. Academic Press, New York, pp. 247-254.

SCHRADER F. 1945a: Regular occurrence of heteroploidy in a group of Pentatomidae (Hemiptera). Biol. Bull. 88: 63-70.

SCHRADER F. 1945b: The cytology of regular heteroploidy in the genus Loxa (Pentatomidae - Hemiptera). J. Morphol. 76: 157-177.

SCHRADER F. 1946: Autossomal elimination and preferential segregation in the harlequin lobe of certain Discocephalini (Hemiptera). Biol. Bull. 90: 264-290.

SCHRADER F. 1960a: Cytological and evolutionary implications of aberrant chromosome behavior in the harlequin lobe of some Pentatomidae (Heteroptera). Chromosoma 11: 103-128.

SCHRADER F. 1960b: Evolutionary aspects of aberrant meiosis in some Pentatomidae (Heteroptera). Evolution 14: 498-508.

Schrader F. \& Leuchtenberger C. 1950: A cytochemical analysis of the functional interrelations of various cell structures in Arvelius albopunctatus (De Geer). Exp. Cell Res. 1: 421-452.

Schrader F. \& Leuchtenberger C. 1951: The cytology and chemical nature of some constituents of the developing sperm. Chromosoma 4: 404-428.

SIVINSKI J. 1980: Sexual selection and insect sperm. Fla Entomol. 63: 99-111.

Suja J.A., Del Cerro A.L., Page J., Rufas J.S. \& Santos J.L. 2000: Meiotic sister chromatid cohesion in holocentric sex chromosomes of three heteropteran species is maintained in absence of axial elements. Chromosoma 109: 35-43.

Swallow J.G. \& Wilkinson G.S. 2002: The long and short sperm polymorphism in insects. Biol. Res. 77: 153-182.

Tartarotti E. \& Azeredo-Oliveira M.T.V. 1999: Meiosis patterns of holocentric chromosomes in Triatomines Genus Panstrongylus. Cytologia 64: 235-240.

Ueshima N. 1979: Hemiptera II: Heteroptera. In: John B. (ed). Animal Cytogenetics. Vol. 3, Insecta 6. Gebrüder Borntraeger, Berlin, Stuttgart, $117 \mathrm{pp}$.

Received October 6, 2006; revised and accepted January 19, 2007 